\title{
INTERNATIONAL SOCIETY FOR GESTALT THEORY AND ITS APPLICATIONS
}

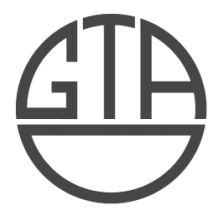

Call for Papers

in cooperation with

The Department of Life Sciences of the University of Trieste

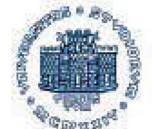

UNIVERSITÀ

DEGLI STUDI DI TRIESTE

$22^{\text {nd }}$ International Scientific Conference

MIND IN CONTEXT - CONTEXT IN MIND

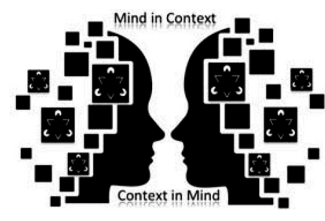

$7^{t h-10^{t h}}$ July 2022

Trieste, Italy

We are pleased to invite you to submit an abstract for your contribution to the $22^{\text {nd }}$ GTA Scientific Conference. 
The conference program will include plenary lectures, working groups, and poster sessions. The topic of the conference "Mind in Context - Context in Mind" discusses the complex relationship between mind and context in its entire breadth of expressions. The focus will be on perception, attention, learning, memory, decisions, reasoning, personality, motivation, emotion, and communication in different areas of experience. The conference is thus decidedly interdisciplinary. Psychologists, linguists, philosophers, phenomenologists, anthropologists, psychotherapists and psychoanalysts, educational and social scientists, but also biologists, physicists, and science theorists as well as artists are welcome to give their contribution to the Conference. We also want to reflect on the relevance of Gestalt theory and how far its approaches can be linked to other contemporary perspectives. The conference language is mainly English.

Invited Speakers will be (not yet completed):

Achille Varzi

Alan Gilchrist

Stefano Piccolo

Massimo Recalcati

Submitted abstracts for oral and poster sessions should not contain $>1,500$ characters (no references are allowed). The deadline for the submission and the registration is March 21, 2022. Groups of researchers (4-5 participants) can jointly propose thematic workshops to the organizers: the deadline is February 28, 2022. Decisions on accepted papers after a double-blind peer review will be announced by April 17, 2022.

If you have any questions, please contact the organizers Tiziano Agostini and Fabrizio Sors (info@gtaconference.com) or see the websites of the Gestalt Theory association (https://www.gestaltheory.net/) and of the Conference (https://gtaconference2022.com)

\section{Conference registration and payment}

Information will be available by November 2021 . 


\section{Conference fees:}

Non-GTA members: $€ 160$

GTA members: $€ 120$

after $15^{\text {th }}$ June: $€ 200$, GTA members: $€ 160$

Students: $€ 40$

Students of University of Trieste: $€ 20$

Purpose of payment: Conference 2022 Trieste, name of the participant.

The conference can be certified as psychological/psychotherapeutic training. Facilitations upon justified requests are available. 